\title{
ANDROMEDOTOXIN IN RHODODENDRONS
}

\author{
N. V. Belova
}

Khimiya Prirodnykh Soedinenii, Vol. 6, No. 3, pp. 388-389, 1970

UDC 547.913.6

From leaf-bearing shoots of Rhododendron Adamsii Rehd. (Adams rhododendron) by extraction with methanol and subsequent precipitation, of impurities with lead acetate according to the method described by Takemoto and Meguri $[1,2]$ we have isolated a substance with $\mathrm{mp} 256-259^{\circ} \mathrm{C}$. It was identified from its IR spectrum, $\mathrm{cm}^{-1}: 1243$ and $1730\left(\mathrm{CH}_{3} \mathrm{COO}\right)$, and $3400(\mathrm{OH})$, and the melting point of its acetylation product as andromedotoxin, grayanotoxin $\mathrm{I}$.

The substance gave no depression of the melting point with the andromedotoxin which we obtained from the flowers of Rh. luteum Sweet. (yellow rhododendron).

By the paper chromatography [4] of preparatively purified ethanolic extracts of rhododendron in a methanolchloroform-water $(1: 7: 2)$ system, andromedotoxin was detected in leaf-bearing shoots of Rh. mucronulatum Turez. and Rh. ledebourii Pojark., and its presence was confirmed in leaf-bearing shoots of Rh. aureum Georgi., in the leaves of Rh. ponticum $\mathrm{L}$, and in the flowers and leaves of Rh. luteum Sweet.

\section{REFERENCES}

1. T. Takemoto et al, J. Pharm. Soc. Japan, 78, 2, 1958.

2. H. Meguri et al, Mem. Osaka Inst. Technol, A13 (2) 57, RZhBKh, 20, F 1056, 1969.

3. Tallent et al., J. Am. Chem. Soc., 79, 16, 4548, 1957.

4. H. Schindler, Planta med., 10, no. 2, 1962.

30 January 1970

Komarov Botanical Institute 